\title{
STUDY ON DETERMINATIONS AND CONNECTIONS IN THE SOCIAL COMPETENCE OF THE LEADER IN THE MILITARY ORGANIZATIONAL CONTEXT
}

\author{
Benoni SFÂRLOG, Daniel-Sorin CONSTANTIN \\ "Nicolae Bălcescu" Land Forces Academy, Sibiu, Romania \\ sfarlogb@yahoo.com, cdanielsorin@gmail.com
}

\begin{abstract}
The military leader is the central pillar of the military structures whose functionalism is sustained and enhanced by the exercise of effective leadership. Explaining the role and place of the military leader in an organizational context creates prerequisites for the identification of his/her action aspects, in situations specific to the military organization at peace or during war. On this basis, it is possible to outline the sphere of competences of the military leader from the point of view of the defining features of the reference level at which the leader exercises his prerogatives. The content of the competences and the correlations established in their integrated system are the basis for operational and formative investigations and substantiation.
\end{abstract}

Keywords: military leadership, military leader, leader's competencies, leader's social competence

1. Considerations on the competences' architecture of the military leader

In the literature, the concept of competence has, on the one hand, a legal connotation (the right of a person/group or authority to decide on a particular issue according to the organizational or social hierarchical level), as well as a professional connotation which means that individual or collective feature of selecting, mobilizing, combining and effectively utilizing, in a given context, an integrated set of knowledge, skills and attitudes of application, operation, and transfer to successfully resolve tasks related to a particular domain [1], as well as those of organizing activities through the way people interrelate. We notice that, in fact, competence is an integrated set of acquisitions that, through networking, results in that individual/collective capacity for practical solutions to various contextual problems.
In the last decades, competence has become the concept of new paradigms in the field of education, which replaces the paradigm centered on goals and objectives as well as in the field of human resources management. Thus it is necessary and useful to investigate the scope of leadership, including the integrated leader on different hierarchical stages in the military structures, in the different situations specific to the military organizational environment.

Jurisdiction demonstrates its applicability in particular as regards the empirical/practical aspect of human activity, the decisive milestone being the action for the successful completion of a series of operations, techniques or procedures. Competence is not a sum of cognitive, aptitude and affective resources, but a combination of these resources in which they are harnessed/empowered to 
complement and sustain one another. There is therefore a need for a holistic, integrative approach that includes, in their complexity, all the factors and connections generating emerging competencies. The concept of competence covers the entire spectrum of human activities and is defining for each area of the social, at all its hierarchical levels, with all competence being explicit and structured on levels that essentially include the possible evolution in career.

In classical management, skills are dealt with in a double perspective [2]. On the one hand, the "having skills" approach with a significance close to the legal meaning of the term, by reference to the functions of management and, on the other hand, the way of "being competent", highlighting the structured set of acquisitions resulting from training, experience and personal capabilities. For the military leader, competence is a mandatory condition for the efficiency of the action, because the essence of his/her role is to influence the behavior of the subordinates. We find that the structure of the military leader's competence has the effect of professional training as a support for the effective exercise of the functions of the management and implicitly of the structural orientation in the execution of the list with the essential requirements of the mission and for the protection of the employees. The competencies of the military leader aims at the general human abilities, as well as the plan of the capacities related to social relation and integration, in the specific conditions of the military environment, the functional roles of each military.

As in any area of activity, the military leader's competences are classified, explicit and operationalized through general personal and social competences and specific professional skills.

The general competencies of the leader refer both to his/her personal knowledge and abilities, but also to those relating to the ability to interact with others, which are essentially social. Personal skills include self-knowledge (emotional self-knowledge, correct self-esteem, self-confidence) and self-control (self-control, transparency, adaptability, ambition, initiative and optimism). The above skill classification is based on the model proposed by Daniel Goleman in "Emotional Intelligence in Leadership".

A successful leader will know how to combine these skills in a balanced way in order to be effective for his organization. Identifying and understanding, using and managing emotions is a dynamic process, any ability influencing the other.

Only a good understanding and use of emotional information can help us to use, accept, manage and implement the emotions that we have or that we perceive. In close connection with emotional selfknowledge, the concept of correct selfevaluation, which derives from the first mentioned concept, is also defined, since good knowledge of self leads to the identification and awareness of own limits, own vulnerabilities and personal strengths. This creates premises for a correct management of the strengths and weaknesses of the individual. Equally, it is possible to use self-evaluation products in the form of self-evaluation, in the sense of potentiating the strengths and weakening the vulnerabilities.

\section{Theoretical aspects on the social competence of the leader}

Emotions are of particular importance in human activity because they largely influence behavior and shape the decisions, judgments and different behaviors of the leader. The military leader will have to act under stress and high risk so he has to master his emotions and remain focused on the mission he has to accomplish and make the right decisions, taking into account that, in case of war, the life of his subordinates depends on this.

Self-control or self-stability, a component of emotional intelligence, is the competence through which a person finds ways to 
control emotional impulses and even channel them for useful purposes. Although emotions have a major influence on how people interact and on the decisions a person takes, as we have said before, the leader must show self-control in any situation. Thus, by means of self-control, the leader will not panic in such situations, but will, on the contrary, take a pause of thinking, calmly analyze the situation and make a decision transmitting the same emotions to the subordinates. Managing own emotions does not mean domination or suppression but their manipulation with a certain degree of skill and flexibility; it also assumes the ability to remain open to feelings, both pleasant and unpleasant. The ability of the leader to control affective feelings and to influence the emotions of those in around is not just a private issue, but it has a major impact on the results of the military structure. Emotions and feelings affect the quantity and quality of people's work. The quality of the feelings determines performance in military structures.

Empathy is essential to the leader's core responsibility, to create resonance. The leader decides what is best to say and do, or to join others when they are joyful or when they have to apprehend fears, soothe anger, because it is necessary to connect to the feelings of others. He understands the common values and priorities that can guide the group. Without empathy, the leader will inadvertently send discordant messages, and his words and deeds will produce negative reactions. Emotion becomes the "sine qua non" element of effective social interactions in professional life. People who are able to empathize are extremely talented to recognize and meet the wishes of their subordinates.

The triad of self-knowledge, self-control and empathy is support for relationship management. Here we find the most obvious tools of leadership: persuasion, conflict management, and collaboration. The competent relationship management is found in managing the emotions of others. For this, leaders need to be aware of their own emotions and to become empathetic with the people they lead. Leaders who know how to cultivate the skills of others show a genuine interest to those they help, understanding their goals, qualities and weaknesses. They can provide timely and constructive opinions, are innate mentors and counselors, are capable of facilitating change, know how to identify or grasp the need for change. They also know how to find practical ways to overcome the barriers to change. Leaders who ideally manage conflicts are able to separate the parties to the conflict, understand the prospect of each, and then find a common ideal for everyone. They bring the conflict to the surface, get to know the feelings and points of view of all parties, and then redirect energy to a common ideal.

\section{Design of the research}

The aim of our study is to identify the determinations and connections that generate and support social competence as well as the predilection for the concrete forms of manifestations of social interactions.

We have set goals for it, as follows: a) identifying the explanatory factors relevant to the social competence of the military leader; b) determining the dominant interactive preferences of military leaders.

The approach of investigating the assumed issues is viable and plausible by formulating hypotheses: a) the military leader's social competence has a multidimensional factorial structure, b) the leader's interactive preferences has is based on the leader's personality structure.

In order to verify the hypotheses and achieve the objectives, we adopted the qualitative research method on a sample of 72 officers, starting with the profession (the first three years). Firstly, we applied the Social Scenarios test, which includes a number of scenarios and some typical behavioural choices [3]. Realistic and 
typical social scenarios can provide useful insights for better self-perception [4]. Subsequently, the data obtained by applying the CPI 462 test led to the outlining of the results regarding the personality factors involved in generating social competence. We have taken into account factors that reflect the specificity of social competence through the meaning of their definitions (Dominance, Status Capability, Sociability, Social Presence, Empathy, Psychological Intuition, Good Impression, Flexibility and Managerial Potential, Leadership).

\section{Brief interpretation of results}

In the first stage, $32 \%$ of subjects fall into the Motor Type, combining high-level social energy with a strong focus on the goal. They tend to take over the order in many situations and to assert their point of view on how to achieve the proposed objective. Another 52\% are representatives of the Stimulator, being people who show high social energy but tend to influence people through personal relationships. The Stimulator usually seeks to unite people and motivate them to achieve the common goal. Stimulators value personal relationships with others and generally emphasize collaboration, engagement, and team spirit. Approximately $13 \%$ of the sample surveyed falls within the Diplomat type, showing lower social energy, preferring to work with people to achieve the goals. By imposing less force and not giving so many indications, Diplomats value cooperation and collaboration and often seek help from others to reach an agreement. I can serve as intermediaries in conflict or controversy situations; $3 \%$ of those interviewed are in the loneliness type combining low social energy with goal-directed approach.

In the second stage, looking at the "Flexibility" scale, we notice that $14 \%$ of the population surveyed scored a small score, these people prefer predictability and consistency, are uncomfortable with ambiguity, and like to have well-planned and scheduled activities, being some organized characters. $60 \%$ of the investigated subjects achieved a high score demonstrating that they like change and variety, consider routine and habit as boring, being able to think fast and can be considered smart.

Studying status capability, $8 \%$ of the subjects have self-confidence, avoiding direct competition, unable to assume their major status or responsibilities, often feeling that life is unfair. $32 \%$ obtained average scores proving they have some selfconfidence, they generally assume major responsibilities and the consequences resulting from the facts. About $60 \%$ proved to be ambitious, wanting to be successful, looking for a prosperous lifestyle, proving a wide variety of interests.

The statistical analysis of the "empathy" scale shows that about $4 \%$ of the subjects under investigation are not good at judging other people, being somewhat reticent, feeling uncomfortable with change and uncertainty, often being misunderstood. The vast majority of investigated subjects $(72 \%)$ appeared to be pleasing individuals, capable of understanding the feelings of others, multilateral, adventurous, and having good social skills.

The analysis of scores on the "psychological intuition" dimension shows that $12 \%$ of the subjects have difficulty in figuring out how others will feel or react, that they are not very interested in the dynamics of behavior, that they look more at what people do than what they think. A large percentage $(73 \%)$ demonstrate that they have an analytical psychological power of penetration over people and their motivation, that they quickly make impressions and always express themselves according to the behavior of others.

The statistical analysis of the "sociability" scale shows that there are no people among the subjects who face major difficulties in the integration process that will always remain in the shadows and keep people away. The vast majority have shown that 
they are sociable, oriented towards relationships with others, being attracted to the opportunity to meet new people, proving a socially enhanced competence.

By analyzing the "Good Impression" scale, we notice that military leaders are careful to present a favorable image to others, that they are polite and usually obey the rules.

After detailed analysis of "social presence", one can see that a $6 \%$ got a low score, subjects proving to be rather cautious, with fear of catching attention, who seem somewhat inhibited, and have a predisposition to a feeling of guilt. The vast majority of investigated subjects demonstrate that they want and seek social attention and recognition, prefer to have audiences, are spontaneous, versatile, and difficult to confuse.

The analysis of scores on the "dominance" dimension shows us that officers fall within the limits of normal. Thus, we do not meet people who feel uncomfortable in exercising their authority, who hesitate to make decisions and who are afraid to exercise their formal authority, but do not fall into the other extreme, that of having an excessive bossy behavior.

To highlight the "Sense of Situation" we took into consideration the following scales: Status Capability, Empathy and Psychological Intuition. Thus, 7\% of the investigated subjects proved that they are not able to read the facts based on the practical knowledge of human nature, that they do not know either the unwritten rules, or the social conventions that govern the various situations. The vast majority $(67 \%)$ have shown that they are open to the feelings, needs and interests of others, that they know how to appreciate the different points of view that others can have and have a practical sense of how people react to stress, conflict and uncertainty.

The analysis of scores on "presence" was done using the Sociability, Good Impression, and Social Presence scales. All subjects tend to give a sense of trust, professionalism, courtesy.
"Authenticity" has been evaluated using the Flexibility and Status Capabilities scales. The analysis shows that $7 \%$ of the subjects are not always authentic, others prove they respect themselves, trust their personal values and beliefs and have a direct and sincere relationship with others.

In the case of the "Clarity" analysis, we considered it necessary to analyze the Social Presence and Dominance scales. More than $92 \%$ of the investigated subjects prove they are able to use language skillfully. They know to listen carefully and skillfully to understand the beliefs of others. However, $8 \%$ demonstrated that they do not possess this dimension of Social Intelligence, being unable to express their thoughts, opinions, ideas and intentions clearly.

"Empathy", studied through the Psychological Intuition, Empathy and Sociability scales, reveals that a relatively small percentage, of $4 \%$, is unable to help establish a sense of connection between them and others to determine them to get closer, not to be distant, rather causing a sense of action that can affect them.

Analyzing the results we can see a very good correlation between the level of development of the interaction capacity and the leadership potential. The analysis of the scores on each investigated dimension highlights the very compatibility between the dimensions of the interaction capacity and the leadership potential. Thus, the working hypotheses were confirmed.

\section{Conclusions}

The results of this research allow multiple references on the multidimensionality of social competence, highlighting variables of cognitive, motivational, personality and behavioral nature. Taking into account the extremely high correlation we have obtained between the degree of development of the social interaction capacity and leadership potential, it must be taken into account that other equally direct or induced factors influence the equation of 
leadership exercise. This does not interfere in the foundation and implementation of integrated and articulated conceptions about the formation and development of the military leader. Organizational needs call for the implementation of effective, carefully managed programs, and especially the rigorous application of formative and career development optimization requirements.
The sample is a small one to be able to make generalizations. However, it may be appreciated that reconsiderations are required as regards the philosophy of the future development of the officers.

[1] Mușata-Dacia Bocoș (coord), Dicționar praxiologic de pedagogie, Editura Paralela 45, București, 2016, p. 221.

[2] Hoffman Oscar, Management: fundamente socio-umane, Editura Victor, Bucuresti, 1999, p. 76.

[3] Karl Albercht, “Inteligenţă socială”, Editura Curtea Veche, Bucuresti, 2007, pp. 192197.

[4] Roco, Mihaela: Creativitate şi inteligenţă emoţională, Iaşi, Editura Polirom, 2004, p. 7. 